House of Commons; Dr. A. H. R. Goldie, deputy director (research), Meteorological Office, Air Ministry; Mr. W. H. Guillebaud, deputy directorgeneral, Forestry Commission; Mr. W. L. M. O'Connor, director of carbonization, National Coal Board; Mr. J. E. Serby, deputy director, Royal Aircraft Establishment, Farnborough ; Prof. A. N. Shimmin, professor of social science in the University of Leeds, for services as a member of the National Arbitration Tribunal ; Dr. S. L. Smith, director of research, British Shipbuilding Research Association; Dr. V. B. Wigglesworth, director of the Unit of Insect Physiology, Agricultural Research Council; Mr. R. Yates, deputy chief inspector of mines, Ministry of Fuel and Power.

\section{Astronomical Observatories at Mount Stromlo, Australia}

For some years the Yale and Columbia Universities have jointly operated a Southern Station at Johannesburg, but they have recently become embarrassed by the deterioration of astronomical observing conditions in that city, due to its industrial development. It became necessary to seek a site in some country locality, and the two American Universities have accepted an offer made by the Australian Government to set up the Station on Mount Stromlo next to the Commonwealth Observatory. It is now planned to move the principal telescope, which is a refractor of $26 \mathrm{in}$. aperture and $400 \mathrm{in}$. focal length, late in 1951, and to erect a wide-field camera of $8 \mathrm{in}$. aperture and $80 \mathrm{in}$. focal length at about the same time. The station will be under the charge of Mr. Cyril Jackson, who will carry out programmes as arranged by the directors of Yale and Columbia Observatories, Dr. Dirk Brouwer (who visited Mount Stromlo in November and December) and Jan Schilt. It is expected, however, that there will be some interchange of observing time with the Commonwealth Observatory.

It is proposed to continue photographic determinations of stellar parallax, proper motions, mass ratios of binary stars and of the positions of minor planets, and photo-electric determinations of stellar magnitude. Provision of a visual correcting lens and of an objective prism for the long-focus refractor is under consideration. This telescope will complement the 74-in. reflecting telescope now being constructed for Mount Stromlo by Messrs. Sir Howard Grubb, Parsons and Co., and the old Melbourne 48-in. telescope which is being re-erected on Mount Stromlo as a Schmidt camera; and it is hoped that cooperation between the Yale-Columbia observers and those of the proposed Swedish observatory on Mount Stromlo with the staff of the Commonwealth Observatory and of the Australian National University will prove fruitful of astronomical results.

\section{Medical Aspects of Atomic Warfare}

THE real danger that atomic warfare may be employed in a further world conflict makes the symposium on its medical aspects, organized by The Practitioner with the advice of Sir Ernest Rock Carling, and published in its December issue, specially timely. Its aim is to provide essential information on the hazards of atom bomb explosions. Ten articles, written by experts, cover very briefly the physical, biological, genetical and medical aspects. The contributors to the symposium have taken advantage of the various official publications and personal reports concerned with the atomic explosions at Hiroshima and Nagasaki. One of the papers deals with the assessment of possible casualties and damage which might be caused by an atom bomb bursting over a British city, and contains many thought-provoking if unpleasant data. A proper distinction is drawn between gross pathological lesions, which are well summarized, and the deleterious genetical effects manifesting themselves only in later generations and the distant future. The information given in these ten articles, though chiefly directed to the medical profession, will undoubtedly be useful to all concerned with our defence and safety. In an editorial comment it is suggested that medical men in possession of such knowledge will be able "to calm the fears of our more apprehensive patients", and keep up the morale of the population; we must, however, remain of the opinion and hope that if this information concerning the consequences of an atom bomb attack is shared by an adequate number of the potential "patients" themselves, the ghastly prospect may yet become sufficiently remote.

\section{Catalogue of Economic and Social Projects of the} United Nations

The "Catalogue of Economic and Social Projects, 1950" (pp. 515; Lake Success, N.Y.: United Nations; London : H.M. Stationery Office, 1950; 3.75 dollars or $27 s .6 d$.), issued by the United Nations secretariat at the request of the Economic and Social Council, lists, describes and classifies the work during 1949 of the secretariats of the United Nations and of the Specialized Agencies in the economic and social fields. The main bulk of the information, which includes research studies and investigations as well as technical services and other operational activities, is set forth under the different departments responsible, first of the United Nations and then of the Specialized Agencies; but the analytical index which constitutes Part 2 of the Catalogue brings together, under headings representing the main sectors of the economic and social field, the work of the United Nations and the Agencies related to each sector. The subject headings, adopted for this classification as a result of consultation among the Agencies and the United Nations, represent a compromise and are regarded as experimental. There is some repetition, but they do assist in giving a fairly coherent picture of the work going on in particular fields, though no complete picture is given of what is taking place in science or in any one branch of science. Although the Catalogue is not primarily a bibliography, much bibliographical information on reports and other published documents is included. Not the least useful features are the two lists appended, giving the libraries where documents of the United Nations and of the Specialized Agencies can be consulted, and U.N. information centres and the sales depots where documents of the Specialized Agencies are available.

\section{Nuffield Foundation Awards for Biology and the Social Sciences}

As an experiment during the next three years, the Nuffield Foundation is offering annually a small number of scholarships and bursaries in biology and in the social sciences (excluding economics) for British graduates of about 22-35 years of age, which will be tenable initially for one year but renewable up to three years. The awards in biology are for persons who have graduated in the physical sciences or in mathematics and who wish to pursue a course of further training in biology. The scholarships are for those with some previous postgraduate experience 